\title{
Twenty Seven
}

National Cancer Institute

\section{Source}

National Cancer Institute. Twenty Seven. NCI Thesaurus. Code C126887.

A natural number greater than twenty-six and less than twenty-eight and the quantity that it denotes. 